\title{
Silver nanoparticles - green synthesis and misconception
}

\section{Introduction}

It is with reference to the research article "Silver nanoparticles to self-assembled films: Green synthesis and characterization" by Zoya Zaheer \& Rafiuddin . ${ }^{1}$ The Uv-vis absorption peak of silver nanoparticles synthesized from oxalic acid and silver nitrate, appearing at $425 \mathrm{~nm}$ has been ascribed to the characteristic extinction coefficient .$^{2}$ of small mono dispersed spherical nanoparticles.$^{3-5}$ although it is ubiquitously known that this absorption is only due to surface plasmon resonance (SPR) of silver nanoparticles. The extinction coefficient, defined as $\mathrm{A}=\mathrm{abc}$ is concentration dependent (where $\mathrm{A}=\mathrm{absorbance}$, $\mathrm{a}=$ absorption coefficient, $\mathrm{b}=$ path length $=1 \mathrm{~cm}, \mathrm{c}=$ concentration) The equation assumes the form, $\mathrm{a}=\mathrm{A} / \mathrm{c}$ where extinction coefficient varies with concentration.

The process of synthesis of silver nanoparticles from oxalic acid and silver nitrate cannot be termed green synthesis. It is a misconception and lack of distinction between chemical synthesis and green synthesis. The authors . ${ }^{1}$ have said, with great conviction that, the exact position of absorption of silver depends on the dielectric constant of the medium without any experimental evidence. However, it is universally known that this absorption band is solely dependent on the surface plasmon vibration of silver nanoparticles and the other compounds present in the solution. It has nothing to do with dielectric constant of the solvent. As the concentration of silver nanoparticles increases, the absorbance also increases (Figure 1) without any change in the $\lambda_{\max }{ }^{1}$

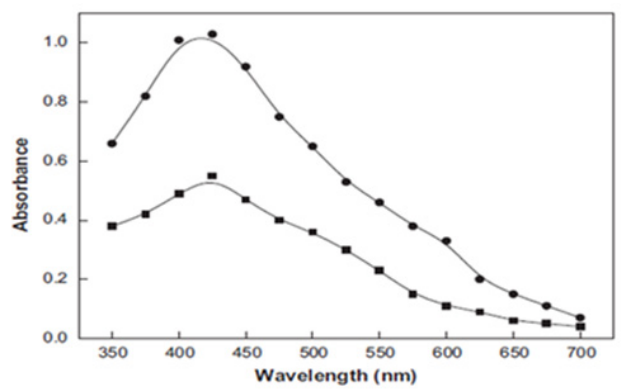

Figure I UV-Visible spectra of yellow color silver sol. Reaction conditions: $\left[\mathrm{Ag}^{+}\right]-200 \times 10^{-4} \mathrm{moldm}^{-3}$; [Oxalic acid] $-4.0 \times 10^{-4} \mathrm{moldm}^{-3} ;$ [CTAB]-10.0 $\times 10-4$ moldm-3;Temperature $-30^{\circ} \mathrm{C}$.

They have argued further, that according to TEM images, the nanoparticles were formed first in the solution, and subsequently aggregated into large particles due to adsorption of $\mathrm{Ag}^{+}$on to the surface of $\mathrm{Ag}^{0}$ through van der Waals forces. It must be made clear that TEM images show shape and size of nanoparticles irrespective of their scattering or aggregation. The adsorption of $\mathrm{Ag}^{+}$on the $\mathrm{Ag}^{0}$ is a matter of metal ion and a metal atom which are available in different quantities in the solution. The van der Waals or London forces are extremely weak forces which keep two neutral atoms such as $\mathrm{He} / \mathrm{Ar}$ or molecules like $\mathrm{CH}_{4}$ together without bearing any charge on them. Such molecules or atoms must have a temporary dipole due to non spherical shape or non spherical distribution of electrons which brings
Volume 6 Issue 3 - 2017

\section{Siddiqi KS,' Rahman A, ${ }^{2}$ Tajuddin ${ }^{2}$}

'Department of Chemistry, Aligarh Muslim University, India ${ }^{2}$ Department of Saidla, Faculty of Unani Medicine, Aligarh Muslim University, India

Correspondence: Siddiqi KS, Department of Chemistry, Aligarh Muslim University, Aligarh-202002, India; Emailsiddiqi@yahoo.co.in

Received: September 19, 2017| Published: October 20, 2017

them together. Silver ions and silver nanoparticles are dispersed and some of them get accumulated but the van der Waals forces are not operative here. The substances in which adjacent molecules / atoms are held together by van der Waals forces are frequently gases at room temperature.$^{6}$ and their boiling points are extremely low (Table 1). The authors.$^{1}$ have proposed the following mechanism for the formation of Silver nanoparticles in aqueous medium at $\mathrm{pH} 3$ (Figure 2).

Table I Contribution to the total van derWaals Lattice Energy in $\mathrm{Kcal} / \mathrm{mole} .^{6}$

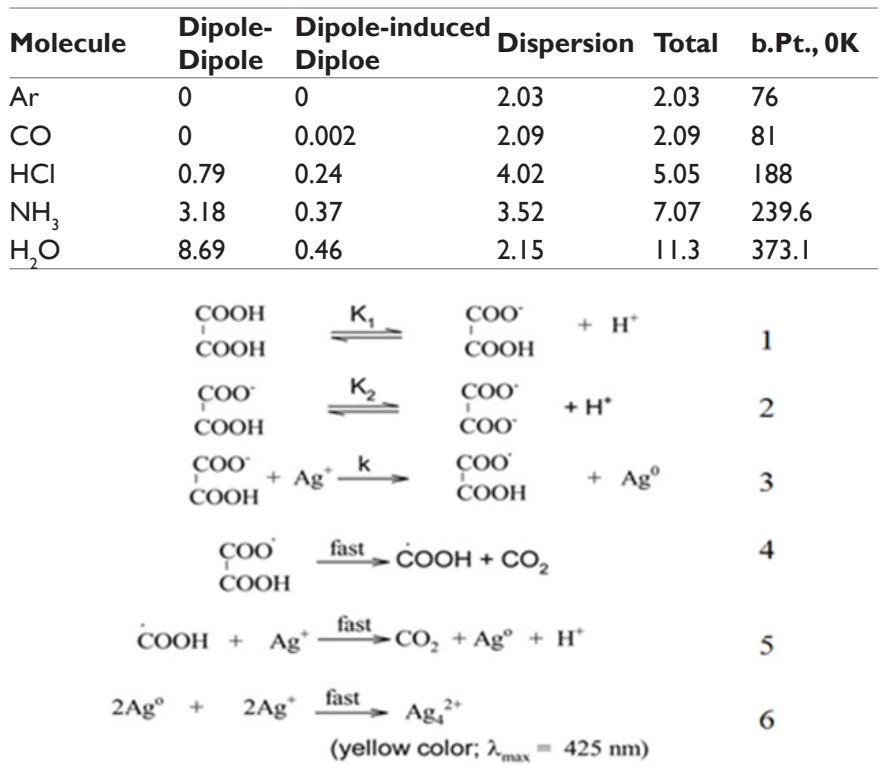

Figure 2 Mechanism for the formation of Silver nanoparticles in aqueous medium at $\mathrm{pH} 3$. 
It is true that oxalic acid is a week acid and hence incompletely ionized but monoionic species (equation 1) will not be stable. It will lose the second proton forming $\mathrm{C}_{2} \mathrm{O}_{4}^{2-}$ ion (equation 2) and subsequently react with silver nitrate to yield silver nanoparticles. Their claim that silver oxalate is not formed when silver nitrate is added to oxalic acid at room temperature at $\mathrm{pH} 3$, is incorrect. We have experimentally investigated that when $10^{-3} \mathrm{M}$ oxalic acid is mixed with $\mathrm{AgNO}_{3}$ or vice versa, a thick white crystalline precipitate is instantaneously formed which settles at the bottom of container. After standing for about $1 \mathrm{~h}$ it reduces silver nitrate to silver nanoparticles and carbon dioxide is released with a simultaneous change in color, according to the following reaction:

$$
\begin{aligned}
2 \mathrm{AgNO}_{3}+(\mathrm{COOH})_{2} & \stackrel{\mathrm{RT}}{\longrightarrow} \mathrm{Ag}_{2} \mathrm{C}_{2} \mathrm{O}_{4}+2 \mathrm{HNO}_{3} \\
\mathrm{Ag}_{2} \mathrm{C}_{2} \mathrm{O}_{4} & \stackrel{140^{\circ} \mathrm{C}}{\Delta} 2 \mathrm{Ag}+2 \mathrm{CO}_{2}
\end{aligned}
$$

However, if it is heated to $140^{\circ} \mathrm{C}$ immediate decomposition occurs leaving behind Silver nanoparticles of dark brown color . ${ }^{7}$ Equation 6 showing the formation of $\mathrm{Ag}_{4}{ }^{2+}$ leading to aggregation / deposition of $\mathrm{Ag}^{+}$ions over $\mathrm{Ag}^{0}$ is likely but $\mathrm{Ag}_{4}{ }^{2+}$ formation is dubious. Recently Zoya Zaheer etal. ${ }^{8}$ have reported green synthesis of silvernanoparticles from Dioscorea deltoidea tuber extract and their characterization by various techniques. They have again suggested that surface plasmon resonance peak is dependent on dielectric constant of the medium . ${ }^{9}$ Unfortunately this reference.${ }^{9}$ has no mention of dielectric constant in the entire manuscript. Unwarranted statement involving dielectric constant is misleading. In fact, the biomolecules present in the tuber and silver nanoparticles are responsible for the surface plasmon resonance band. It has been suggested that $\mathrm{Ag}^{0}$ reacts with $\mathrm{Ag}^{+}$to form $\mathrm{Ag}_{2}{ }^{+}$which dimerizes to $\mathrm{Ag}_{4}{ }^{2+}$. As given in their previous paper . ${ }^{1}$ it has neither experimental proof nor it is a convincing hypothesis.

\section{Conflicts of Interest}

The authors declare no conflict of interest.

\section{Acknowledgments}

None.

\section{References}

1. Zoya Zaheer, Rafiuddin Silver nanoparticles to self-assembled films: Green synthesis and characterization. Colloids Surfs B: Biointerfaces. 2012;90:48-52.

2. Gudiksen MS, Lieber CM Diameter-Selective Synthesis of Semiconductor Nanowires J Am Chem Soc. 2000;122(36):8801-8802.

3. Henglein A Physicochemical properties of small metal particles in solution: microelectrode reactions, chemisorption, composite metal particles, and the atom-to-metal transition. J Phys Chem. 1993;97(21):5457-5471.

4. Hanglein A Colloidal Silver Nanoparticles: Photochemical Preparation and Interaction with $\mathrm{O} 2, \mathrm{CCl}$, and Some Metal Ions. Chem Mater. 1998;10(1):444-550.

5. Kim DW, Shin SI, Oh SG Surfactant Sciences Series. In: Mittal KL \& Shah DO (Eds.), Marcel Dekker, New York, USA, pp. 2003;255.

6. M Clyde Day, Joel Selbin Theoretical Inorganic chemistry. (2nd edn), Affiliated East West Press Pvt. Ltd., India, pp. 1971;210.

7. Navaladian S, Viswanathan B, Viswanath R et al. Thermal decomposition as route for silver nanoparticles. Nanoscale Res Lett. 2007;2(1):44-48.

8. Zaheer Z, Aazam ES, Hussain S Reversible encapsulation of silver nanoparticles into the helix of amylose (water soluble starch). Royal Society of Chemistry. 2016;6:60513-60521.

9. Bakshi MS Nanoshape Control Tendency of Phospholipids and Proteins: Protein_Nanoparticle Composites, Seeding, Self-Aggregation, and Their Applications in Bionanotechnology and Nanotoxicology. $J$ Phys Chem C. 2011;115:13947-13960. 